\title{
BMJ Open Primary Sjögren's syndrome 1976-2005 and associated interstitial lung disease: a population-based study of incidence and mortality
}

\author{
Carlotta Nannini, ${ }^{1,2}$ Adlene J Jebakumar, ${ }^{1}$ Cynthia S Crowson, ${ }^{3,4}$ Jay H Ryu, ${ }^{5}$ \\ Eric L Matteson ${ }^{1,4}$
}

To cite: Nannini C, Jebakumar AJ, Crowson CS et al. Primary Sjögren's syndrome 1976-2005 and associated interstitial lung disease: a population-based study of incidence and mortality. BMJ Open 2013;3: e003569. doi:10.1136/ bmjopen-2013-003569

- Prepublication history for this paper is available online. To view these files please visit the journal online (http://dx.doi.org/10.1136/ bmjopen-2013-003569).

Received 8 July 2013 Revised 8 October 2013 Accepted 4 November 2013

CrossMark

For numbered affiliations see end of article.

Correspondence to Dr Carlotta Nannini; nannini.carlotta@gmail.com

\section{ABSTRACT}

Objective: A very few studies describe the epidemiology of primary Sjögren's syndrome (pSS). The reported frequency of pulmonary involvement in pSS varies widely depending on the detection method employed, and consists mainly of various forms of airways disease. We aimed to evaluate the incidence and mortality of pSS and of lung disease in pSS, focusing on interstitial lung disease (ILD).

Methods: A population-based incidence cohort of patients diagnosed with pSS in 1976-2005 was assembled. Diagnosis was based on the 2002 American-European Consensus Group criteria for pSS. Cumulative incidence adjusted for the competing risk of death was estimated. A Cox model with a timedependent covariate was used to determine the incidence and the standardised mortality HR of pSS.

Results: 85 patients with pSS were identified (mean age 59.9 years; $91 \%$ women). The annual incidence of $p S S$ was $4.2,95 \% \mathrm{Cl}$ (3.3 to 5.1)/100 000 population and it increased with higher age at pSS diagnosis (18-44 years: $2.1 / 100000$ vs $\geq 75$ years: $12.3 / 100000$ ). Standardised mortality ratio in pSS compared with the general population was $0.92,95 \% \mathrm{Cl}(0.57$ to 1.41$)$. A total of 105 patients with pSS and ILD were identified (mean age 58.1 years; $91 \%$ women). Among patients with pSS without prior ILD, the cumulative incidence of ILD in patients with $p S S$ was $10 \%( \pm 3 \%)$ at 1 year after diagnosis of pSS and increased to $20 \%( \pm 4 \%)$ by 5 years after pSS. The development of lung disease in pSS was associated with poor survival (HR 2.16; $95 \% \mathrm{Cl} 0.99$ to 4.74).

Conclusions: pSS incidence seems to be almost the same as was reported in a previous study conducted among Olmsted County Minnesota population. Survival among patients with pSS and general population does not differ substantially. However, patients with pSS who have ILD likely have increased premature mortality.

\section{INTRODUCTION}

Sjögren's syndrome (SS) is a chronic autoimmune and systemic inflammatory disease that affects exocrine and extraglandular tissues. ${ }^{1}$ It is

\section{Strengths and limitations of this study}

- This is a population-based study, therefore we tried to do a real estimation of incidence and mortality among patients with primary Sjögren's Syndrome (pSS) and to report the incidence of interstitial lung disease (ILD) among patients with pSS and what is its impact on pSS morality.

- Attention to the occurrence of, and the improved management of, ILD in patients with pSS may contribute to the reduction of disease burden.

- The major concern is related to the chart reviewbased diagnosis; our estimates could not reflect the full extent of ILD in this population. The limited information on tests of lung disease available for each patient inherent to a retrospective study and the unavailability of some information due to time trend effects may lead to a misclassification bias.

- Moreover, an overestimation of lung involvement in participants with pSS compared to those without pSS (surveillance bias) could be present.

- pSS incidence seems to be almost the same as was reported in a previous study conducted among Olmsted County Minnesota population.

- Survival among patients with pSS and general population does not differ substantially.

- Patients with pSS who have ILD most likely have an increased premature mortality.

known to occur alone (primary) or in association with other autoimmune disease states.

A very few studies describe the epidemiology of primary SS (pSS).

The published studies of pSS in the general population report highly heterogeneous results. The wide-ranging prevalence estimates in adults varied from $0.098 \%$ to $3.59 \%$ while the incidence ranged from 3.9 to $5.3 / 100000$ population. ${ }^{2}{ }^{3}$ This wide 
variation is due to the diverse populations using a restricted age range, ${ }^{4}$ low sample size ${ }^{5}$ or low follow-up rate. ${ }^{6}$ The studies of SS also have used a variety of classification criteria leading to difficulties when trying to compare the results.

Extraglandular manifestations of pSS include a broad spectrum of lung disease. The reported frequency of pulmonary involvement in pSS varies widely ranging from $8 \%$ to $75 \%$ depending on the detection method employed, and consists of various forms of airways disease (bronchiectasis, obstructive airways disease) and interstitial lung disease (ILD). ${ }^{7}$ Lymphocytic interstitial pneumonia is well defined in patients with $\mathrm{pSS},{ }^{8}$ but there is relatively little information regarding other ILD patterns occurring in pSS in terms of frequency and risk factors.

Extra-articular disease manifestations, including various forms of lung disease, are common in pSS and may be linked to an increased mortality. ${ }^{9}$ Asymptomatic pulmonary changes are present in a majority of patients, but their impact on the disease course, mortality and quality of life remains unclear.

Most studies have concentrated on ILD in consecutive samples of patients with pSS in academic centres. ${ }^{79-12}$ Consequently, a little is known about the incidence of the full spectrum of respiratory system involvement in a representative sample of patients with pSS from a population-based cohort. Previous studies that examined the incidence or prevalence of pSS-associated lung disease have differed widely in their estimates. This wide variance appears to be due to different diagnostic modalities used to detect the disease, the changed criteria for the classification of SS, previous failure to separate out patients with primary or secondary SS and referral bias in studies originating from large academic centres.

In non-population-based studies, pulmonary changes can be documented in a majority of patients with $\mathrm{pSS}^{10-12}$ and clinically overt ILD is present in $6-94 \%$ in early and longstanding pSS. ${ }^{7}{ }^{10-12}$ There are no population-based estimates of the incidence of pSS and the incidence of pSS-associated ILD. Here, we report on the incidence, and impact on survival of ILD among Olmsted County, Minnesota residents with pSS.

\section{PATIENTS AND METHODS}

This was a retrospective medical record review to investigate the ILD in patients with pSS in Olmsted County, Minnesota, diagnosed during the 45 years period from 1 January 1976 to 31 December 2005 and then followed until death, migration or 31 December 2011.

The population of Olmsted County, Minnesota is well suited for investigation of long-term outcomes of patients with pSS. A medical records linkage system, the Rochester Epidemiology Project (REP), allows a ready access to the complete (inpatient and outpatient) records from all healthcare providers for the local population, including the Mayo Clinic and its affiliated hospitals, the Olmsted Medical Center and its affiliated community hospital, local nursing homes and a few private practitioners. The potential of this data system for population-based research has been previously described. ${ }^{13}{ }^{14}$ This system ensures a virtually complete clinical and vital status information on all clinically recognised cases of pSS among Olmsted County residents.

\section{Ascertainment of pSS cases}

Using this data resource, a population-based incidence cohort of all cases of pSS, first diagnosed between 1 January 1976 and 31 December 2005, among Olmsted County, Minnesota residents $\geq 18$ years of age was assembled. The cohort initially assembled between 1976 and 1992 was enriched adding new patients with pSS diagnosed between 1993 and 2005. ${ }^{3}$ All cases fulfilled the 2002 American-European Consensus Group (AECG) diagnostic criteria for pSS. ${ }^{15}$ Incidence date is defined as the first date of fulfilment of four of the six AECG diagnostic criteria.

All participants were followed up longitudinally through their complete medical records beginning at age 18 (or date of migration to Olmsted County for those who became residents after age 18) and continuing until death, migration from Olmsted County or 31 December 2011.

\section{Data collection}

The original and complete medical records of each patient with pSS were reviewed by $\mathrm{CN}$ and AJJ. Uncertainties regarding the classification of pSS, presence and type of pulmonary disease and underlying disease were adjudicated by JHR and/or ELM.

We abstracted demographic data (date of birth and gender), smoking status at pSS incidence date (never smoked/former smoker/current smoker) and smoking status at diagnosis of lung disease (never smoked/ former smoker/current smoker). The date of last follow-up as well as the status at the last follow-up (dead/alive) was recorded.

SS features were abstracted, and they included time variables (year of symptom onset, year of diagnosis according to the AECG diagnostic criteria),${ }^{15}$ ocular and oral gland involvement (clinical judgement, Schirmer test, salivary glands biopsy and salivary scintigraphy) and laboratory features (rheumatoid factor (RF), antinuclear antibody (ANA), anti-SSA, anti-SSB and IgG level).

\section{Definition and ascertainment of ILD}

The ascertainment of ILD was based on clinical data, pulmonary function test results (total lung capacity, forced vital capacity, forced expiratory volume in $1 \mathrm{~s}$, diffusing capacity for carbon monoxide, $\mathrm{SaO}_{2}$, at rest and with exercise), radiological studies (chest radiographs, CT), bronchoalveolar lavage and lung biopsy. The 


\begin{tabular}{|c|c|}
\hline Probable ILD & $\begin{array}{l}\text { Chest radiograph or CT described as } \\
\text { 'fibrosis' or 'consistent with ILD or } \\
\text { parenchymal lung disease' } \\
\text { or } \\
\text { Physician's diagnosis of 'interstitial lung } \\
\text { disease', 'pulmonary fibrosis', 'interstitial } \\
\text { pneumonia', etc }\end{array}$ \\
\hline Definite ILD & $\begin{array}{l}\text { Diagnosis of ILD by a pulmonologist, } \\
\text { based on chest radiograph/high } \\
\text { resolution chest CT and pulmonary } \\
\text { function testing (restrictive ventilatory } \\
\text { pattern or reduced DLCO) } \\
\text { or } \\
\text { Lung biopsy (bronchoscopic or surgical) }\end{array}$ \\
\hline
\end{tabular}

criteria used to classify ILD were validated in a previous study, and are given in table $1 .^{16}$

\section{Statistical analysis}

Descriptive statistics (means, medians, proportions, etc) were used to summarise the data. Comparison of patient characteristics between time periods was performed using $\chi^{2}$ tests for categorical characteristics and Wilcoxon rank sum tests for continuous characteristics.

The overall incidence rates were age-adjusted and/or sex-adjusted to the 2000 white population of the USA. Age-specific and sex-specific incidence rates were calculated by using the number of incident cases as the numerator and population estimates based on decennial census counts as the denominator, with linear interpolation used to estimate population size for intercensal years. ${ }^{17}$ In order to compute $95 \%$ CI for incidence rates, it was assumed that the number of incident cases followed a Poisson distribution. Trends in incidence rates were examined using Poisson regression methods using smoothing splines for age and calendar year. ${ }^{18}$

The percentage of patients with pSS with respiratory system involvement at pSS incidence date was computed.
Those with respiratory system involvement at pSS incidence date were excluded from the analysis of cumulative incidence. The cumulative incidence of respiratory system involvement (and subtypes) was estimated using product-limit life table methods, accounting for the competing risk of death. ${ }^{19}$

Product-limit life table methods were used to estimate the survival of patients with pSS. The expected number of deaths was determined from the National Center for Health Statistics life tables for the USA population, according to the age, sex and calendar year of the pSS cohort. ${ }^{20}$ A standardised mortality ratio (SMR) was estimated by dividing the observed number of deaths by the expected number of deaths. Ninety-five per cent CIs for the SMR were calculated assuming that the expected rates were fixed and the observed rates followed a Poisson distribution. A Cox model was used to examine the impact of respiratory system involvement on mortality with a time-dependent covariate indicating the development of respiratory system involvement (whereby patients were modelled as unexposed during the follow-up time prior to development of respiratory system involvement and were then modelled as exposed following the development of respiratory system involvement) and adjustment for age, sex and calendar year of diagnosis of pSS. Statistical analysis was performed using SAS software (V.9.3, SAS Institute Inc, Cary, North Carolina, USA).

\section{RESULTS}

We identified 105 patients with incident pSS with a mean age at pSS diagnosis of 58.1 years (range 23-95); $91 \%$ were women. Demographic data and general characteristics of the study population are reported in tables 2-4.

Considering the time periods, patients differ significantly with regard to laboratory evaluation: RF, ANA, anti-SSA and anti-SSB were significantly more frequently detected in the 1993-2005 time period compared with the 1976-1992 cohort. Among clinical features, ocular signs tended towards statistical significance in 1993-2005 period with a $\mathrm{p}$ value of 0.06 .

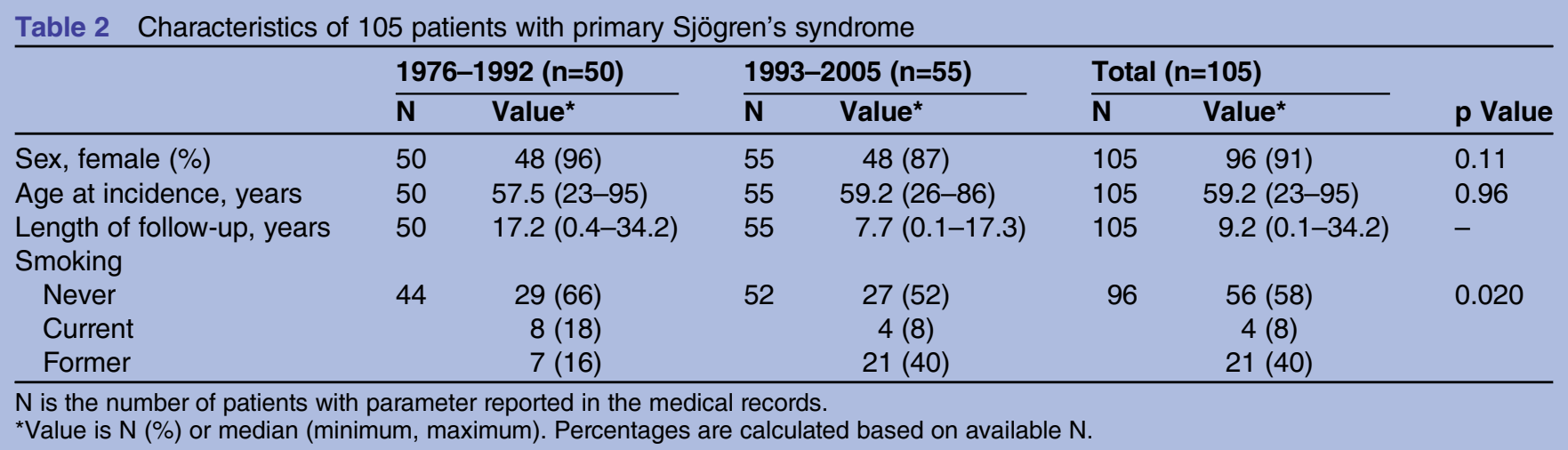


Table 3 Laboratory assessment of 105 patients with primary Sjögren's syndrome

\begin{tabular}{|c|c|c|c|c|c|c|c|}
\hline & \multicolumn{2}{|c|}{$\begin{array}{l}1976-1992 \\
(n=50)\end{array}$} & \multicolumn{2}{|c|}{$\begin{array}{l}1993-2005 \\
(n=55)\end{array}$} & \multicolumn{2}{|c|}{ Total $(n=105)$} & \multirow[b]{2}{*}{ p Value } \\
\hline & $\overline{\mathbf{N}}$ & Value $^{\star}$ & $\overline{\mathbf{N}}$ & Value $^{\star}$ & $\overline{\mathbf{N}}$ & Value* & \\
\hline Rheumatoid factor, positive (\%) & 37 & $14(38)$ & 45 & $32(71)$ & 82 & $46(56)$ & 0.002 \\
\hline Antinuclear antibodies, positive (\%) & 37 & $20(54)$ & 52 & $42(81)$ & 89 & $62(70)$ & 0.007 \\
\hline Anti-SSA, positive (\%) & 17 & $7(41)$ & 48 & $38(79)$ & 65 & $45(69)$ & 0.004 \\
\hline Anti-SSB, positive (\%) & 18 & $6(33)$ & 48 & $30(63)$ & 66 & $36(55)$ & 0.034 \\
\hline Hypergammaglobulinaemia, present (\%) & 38 & $16(42)$ & 44 & $26(59)$ & 82 & $42(51)$ & 0.12 \\
\hline Histopathology, available (\%) & 0 & - & 6 & $3(50)$ & 6 & $3(50)$ & - \\
\hline
\end{tabular}

$\mathrm{N}$ is the number of patients with parameter reported in the medical records.

*Value is $\mathrm{N}(\%)$ or median (minimum, maximum). Percentages are calculated based on available $\mathrm{N}$.

The annual incidence of pSS was 5.1 (95\% CI 4.1 to $6.1) / 100000$ population, and increased with higher age at pSS diagnosis (18-44 years: $1.8 / 100000$ vs $\geq 75$ years: $10.7 / 100000$; table 5). Female patients were more affected $(8.7 / 100000$ population (95\% CI 6.9 to 10.4$)$ ) compared with male patients $(1.1 / 100000(95 \%$ CI 0.4 to 1.9 ; table 5)).

The overall incidence increased modestly during the study period (3.9 (95\% CI 2.2 to 5.6)/100 000 population in 1976-1985; 5.0 (95\% CI 3.3 to 6.7 ) in 1986-1995; and 5.9 (95\% CI 4.2 to 7.6 ) in 1996-2005; linear trend $\mathrm{p}=0.06$; table 6 and figure 1 ).

During a median follow-up of 9.2 years (1205 total person-years), 25 patients died. This was similar to the 29.5 expected deaths (SMR: $0.85,95 \%$ CI 0.55 to 1.25 ), logrank $\mathrm{p}$ value $=0.41$ (figure 2).

\section{ILD in pSS}

Lung disease was present prior to the diagnosis of pSS in 12 patients and developed after diagnosis of pSS in 35 patients with a median follow-up time of 9.2 years (1205 total person-years). Among patients with pSS without prior ILD, the cumulative incidence of ILD in patients with pSS was $10 \%( \pm 3 \%)$ at 1 year after diagnosis of pSS and increased to $20 \%( \pm 4 \%)$ by 5 years, and $43 \%( \pm 7 \%)$ by 15 years after pSS onset. The development of lung disease in pSS was associated with poor survival with an
HR of 2.16 (95\% CI 0.99 to 4.74 ) adjusted for age, sex and calendar year although this did not reach the statistical significance. ILD was identified as the most frequent type of lung disease detected at or after pSS diagnosis (53\%) followed by emphysema (13\%).

\section{DISCUSSION}

We found that the annual incidence of pSS was 5.1 (95\% CI 4.1 to 6.1)/100 000 population and increases with higher age at pSS diagnosis (18-44 years: 1.8/ 100000 vs $\geq 75$ years: $10.7 / 100000$ ). Comparison to existing epidemiological studies is complicated by differences in disease definition and classification criteria. Until now only three studies have evaluated the incidence of $\mathrm{pSS}$ in general population, reporting values from 3.9 to $5.3 / 100000$ population. ${ }^{321} 22$

We found that the incidence of pSS may have increased modestly during the study period with a linear trend $\mathrm{p}$ value of 0.06 , although the overall trend is almost stable despite the differences among the diagnostic criteria occurring over the years. pSS has an incidence peak between 55 and 74 years of age with women more frequently affected than men.

The risk of death in patients with pSS in our study is similar to that in the general population $(0.85 ; 95 \%$ CI 0.55 to 1.25$)$. A prospective study conducted in Greece reported a higher risk of mortality in patients with pSS

Table 4 Clinical characteristics of 105 patients with primary Sjögren's syndrome

\begin{tabular}{|c|c|c|c|c|c|c|c|}
\hline & \multicolumn{2}{|c|}{$\begin{array}{l}1976-1992 \\
(n=50)\end{array}$} & \multicolumn{2}{|c|}{$\begin{array}{l}1993-2005 \\
(n=55)\end{array}$} & \multicolumn{2}{|c|}{ Total $(n=105)$} & \multirow[b]{2}{*}{ p Value } \\
\hline & $\overline{\mathbf{N}}$ & Value* & $\overline{\mathbf{N}}$ & Value $^{\star}$ & $\overline{\mathbf{N}}$ & Value $^{\star}$ & \\
\hline Ocular symptoms, present (\%) & 48 & $45(94)$ & 54 & $52(96)$ & 102 & $97(95)$ & 0.55 \\
\hline Oral symptoms, present (\%) & 45 & $42(93)$ & 50 & $48(96)$ & 95 & $90(95)$ & 0.56 \\
\hline Ocular signs, present (\%) & 30 & $30(100)$ & 9 & $8(89)$ & 39 & $38(90)$ & 0.06 \\
\hline Oral signs, present (\%) & 46 & $3(7)$ & 1 & $0(0)$ & 47 & $3(6)$ & - \\
\hline Ocular signs/symptoms, present (\%) & 48 & $45(94)$ & 54 & $52(96)$ & 102 & $97(95)$ & 0.55 \\
\hline Oral signs/symptoms, present (\%) & 49 & $42(86)$ & 50 & $48(96)$ & 99 & $90(91)$ & 0.08 \\
\hline
\end{tabular}

$\mathrm{N}$ is the number of patients with parameter reported in the medical records.

${ }^{*}$ Value is $\mathrm{N}(\%)$ or median (minimum, maximum). Percentages are calculated based on available $\mathrm{N}$. 
Table 5 Annual incidence of primary Sjögren's syndrome diagnosed between 1976 and 2005 in Olmsted County, Minnesota Residents $\geq 18$ years of age, by sex and age group*

\begin{tabular}{|c|c|c|c|c|c|c|}
\hline \multirow[b]{2}{*}{ Age group } & \multicolumn{2}{|l|}{ Male $(n=9)$} & \multicolumn{2}{|c|}{ Female $(n=96)$} & \multicolumn{2}{|c|}{ Total $(\mathrm{N}=105)$} \\
\hline & $\begin{array}{l}\text { Number of } \\
\text { patients }\end{array}$ & $\begin{array}{l}\text { Rate per } \\
100000\end{array}$ & $\begin{array}{l}\text { Number of } \\
\text { patients }\end{array}$ & Rate per 100000 & $\begin{array}{l}\text { Number of } \\
\text { patients }\end{array}$ & $\begin{array}{l}\text { Rate per } \\
100000\end{array}$ \\
\hline 18-44 years & 3 & 0.5 & 22 & 3.1 & 25 & 1.8 \\
\hline $45-54$ years & 1 & 0.5 & 20 & 10.6 & 21 & 5.6 \\
\hline 55-64 years & 0 & 0.0 & 20 & 15.3 & 20 & 7.9 \\
\hline $65-74$ years & 1 & 1.3 & 21 & 21.8 & 22 & 12.7 \\
\hline$\geq 75$ years & 4 & 7.5 & 13 & 12.3 & 17 & 10.7 \\
\hline $\begin{array}{l}\text { Total }(95 \% \\
\mathrm{Cl})\end{array}$ & 9 & $1.1(0.4$ to 1.9$) \dagger$ & 96 & $8.7(6.9$ to 10.4$) \dagger$ & 105 & $5.1(4.1$ to 6.1$) \ddagger$ \\
\hline
\end{tabular}

compared with that in the general population (SMR 2.07; $95 \%$ CI 1.03 to 3.71$).{ }^{21}$ However, when patients with adverse predictors (low levels of C4, presence of mixed monoclonal cryoglobulins and purpura) were excluded the mortality rate was identical to the general population (SMR 1.02). ${ }^{23}$

Similar to our study, most other studies reported an SMR that range between 1.2 and 1.42 without reaching a statistical significance. ${ }^{324} 25-27$ Therefore the survival of these patients is comparable with that of the general population. $^{28} 29$

Case findings was based on 2002 AECG criteria, used for this study since the cohort was assembled in two time periods, 1976-1992 and 1993-2005. Owing to the new 2012 published expert consensus approach for pSS classification criteria, ${ }^{30}$ feature increased reliance on serological evaluation compared with the older criteria, we were concerned that our study would be affected by the time trend effects affecting classification and therefore used the AECG criteria. Nonetheless, clinical features important in classification have remained unchanged in the two time periods reported in table 4 .

Lung involvement in pSS represents one of the most intriguing aspects of the disease. In this study, patients with pSS without prior ILD have a cumulative incidence of ILD of $10 \%( \pm 3 \%)$ at 1 year after diagnosis of pSS, which increases to $20 \%( \pm 4 \%)$ by 5 years after the onset of pSS.
Patients who developed ILD prior to their pSS diagnosis were calculated apart from our primary analysis in order to avoid any incidence-prevalence bias. Therefore, the overall risk for individuals with pSS to be affected by ILD either prior or after their diagnosis of pSS will be somewhat higher than our estimate. In addition, patients with pSS have more frequent physician visits than the average patient in the population, and physicians may be more attuned to the possibility of lung disease in patients with pSS than in healthy people, leading to an overestimation of lung involvement in participants with pSS compared with those without pSS (surveillance bias).

In contrast to these population-based estimates, the existing literature on ILD and pSS is based on the studies of ILD prevalence in consecutive series of patients with pSS in the academic centres. In non-population-based studies, pulmonary changes can be documented in a majority of patients with $\mathrm{pSS},{ }^{10-12}$ and clinically overt ILD is present in $6-94 \%$ of patients, in early and longstanding $\mathrm{pSS}^{7}{ }^{10-12}$ This wide variance appears to be due to different diagnostic modalities used to detect the disease, the changed criteria for the classification of SS, previous failure to separate out patients with primary or secondary SS and referral bias in studies originating from large academic centres.

Patients with pSS and ILD have a worse survival rate (HR 2.16; $95 \%$ CI 0.99 to 4.74 ). This is in contrast to a

Table 6 Annual incidence of primary Sjögren's syndrome diagnosed between 1976 and 2005 by decade in Olmsted County, Minnesota residents $\geq 18$ years of age, by sex and age group*

\begin{tabular}{|c|c|c|c|c|c|c|}
\hline \multirow[b]{2}{*}{ Age group } & \multicolumn{2}{|l|}{ Male $(n=9)$} & \multicolumn{2}{|c|}{ Female $(n=96)$} & \multicolumn{2}{|c|}{ Total $(\mathrm{N}=105)$} \\
\hline & $\begin{array}{l}\text { Number of } \\
\text { patients }\end{array}$ & $\begin{array}{l}\text { Rate per } \\
100000\end{array}$ & $\begin{array}{l}\text { Number of } \\
\text { patients }\end{array}$ & $\begin{array}{l}\text { Rate per } \\
100000\end{array}$ & $\begin{array}{l}\text { Number of } \\
\text { patients }\end{array}$ & $\begin{array}{l}\text { Rate per } \\
100000\end{array}$ \\
\hline 1976-1985 & 1 & $0.7(0.0$ to 2.2$) \dagger$ & 20 & 6.8 (3.8 to 9.9$) \dagger$ & 21 & $3.9(2.2$ to 5.6$) \ddagger$ \\
\hline 1986-1995 & 1 & $0.6(0.0$ to 1.6$) \dagger$ & 34 & 9.1 (6.0 to 12.2$) \dagger$ & 35 & 5.0 (3.3 to 6.7$) \ddagger$ \\
\hline 1996-2005 & 7 & $1.9(0.4$ to 3.3$) \dagger$ & 42 & $9.5(6.6$ to 12.4$) \dagger$ & 49 & $5.9(4.2$ to 7.6$) \ddagger$ \\
\hline
\end{tabular}

${ }^{*}$ Values are the annual incidence rates $(95 \% \mathrm{Cl})$ per 100000 population.

†Age adjusted to the 2000 US white population.

$\ddagger$ Age and sex adjusted to the 2000 US white population. 


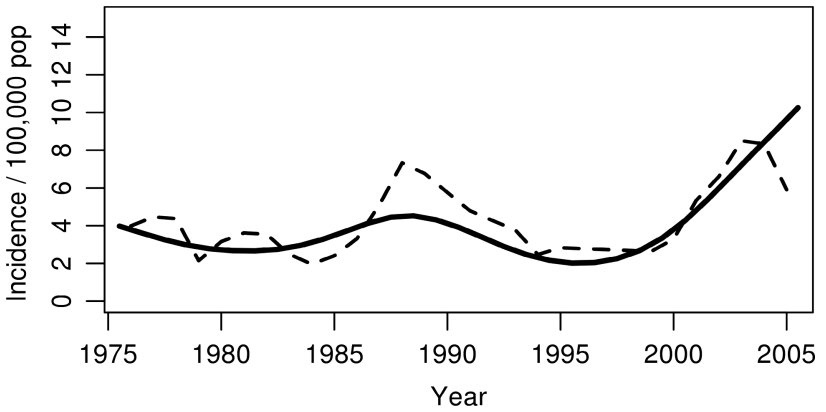

Figure 1 Annual incidence of primary Sjögren's syndrome per 100000 populations in residents of Olmsted County, Minnesota, 1976-2005. The broken line was calculated as a 3-year-centered moving average, and the solid line depicts trends in the incidence rates after adjustment for age and sex (linear trend $\mathrm{p}=0.06$ ).

prospective cohort study which did not find increased all-cause mortality in patients with pSS compared with the general population. ${ }^{24}$ In a retrospective study conducted at Mayo Clinic among 18 patients who underwent lung biopsies, seven patients (39\%) died, including three deaths from acute exacerbation. ${ }^{7}$

Important limitations of our retrospective study approach should be acknowledged. Owing to the inherent limitations of a chart review-based diagnosis, it is likely that our estimates do not reflect the full extent of ILD in this population. The limited information on tests of lung disease (including radiographs, CT and pulmonary function testing) available for each patient inherent to a retrospective study and the unavailability of some information due to time trend effects (eg, CT became available in the 1970s) may lead to a misclassification bias. However, the use of rigorous criteria for ILD diagnosis established by the collaboration between an expert pulmonologist and rheumatologist should have reduced the possibility of this bias.

Our definition of ILD does represent a blend of many different types of parenchymal lung disease. Owing to the changes in availability of diagnostic tools such as CT

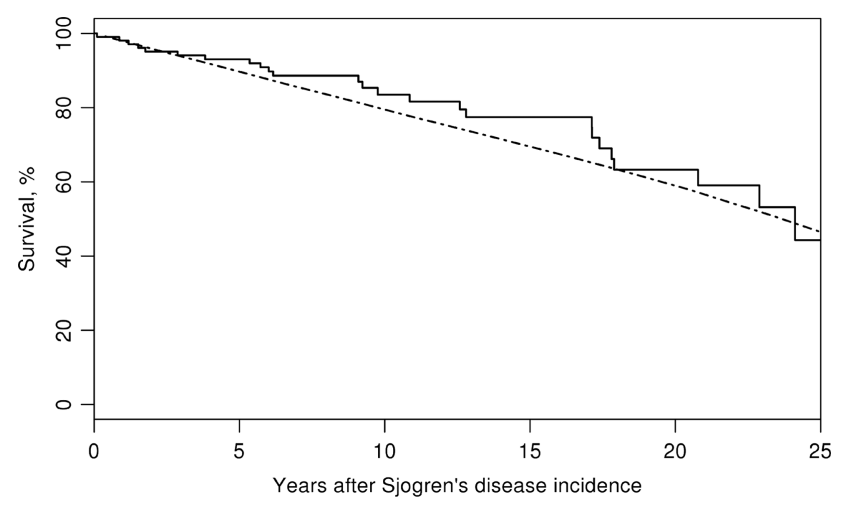

Figure 2 Survival in patients with primary Sjögren's (solid line) compared with the general population (dotted line; logrank $\mathrm{p}=0.41$ ). over time as well as the evolution of definitions used to characterise ILD, reliable assignment of ILD subtypes for every patient according to the most recent American Thoracic Society consensus classification ${ }^{31}$ was not possible.

In conclusion, the incidence of pSS, evaluated using the new ACR classification criteria for pSS, was similar to that reported in a previous study from the same population based on physician diagnosis. The incidence of pSS appears to be increasing in recent years. Our findings emphasise the high incidence of ILD among patients with pSS, and the adverse effect of this disease complication on survival. Patients with pSS should be carefully assessed for diagnosis and management of ILD in order to improve the detrimental survival experience.

Author affiliations

${ }^{1}$ Division of Rheumatology, Mayo Clinic College of Medicine, Rochester, Minnesota, USA

${ }^{2}$ Department of Internal Medicine, Division of Rheumatology, Prato Hospital, Prato, Italy

${ }^{3}$ Division of Biostatistics, Mayo Clinic College of Medicine, Rochester, Minnesota, USA

${ }^{4}$ Department of Health Sciences Research, Mayo Clinic College of Medicine, Rochester, Minnesota, USA

${ }^{5}$ Division of Pulmonary and Critical Care Medicine, Mayo Clinic College of Medicine, Rochester, Minnesota, USA

Contributors All the authors took part in the conception and design, acquisition of data, analysis and interpretation of data, drafting the article or revising it critically for important intellectual content, and approved the final version published.

Funding This work was made possible by the Rochester Epidemiology Project (R01 AG034676 from the National Institute on Aging).

Competing interests None.

Patient consent Obtained.

Ethics approval The study was approved by the institutional review boards at Mayo Clinic and Olmsted Medical Center.

Provenance and peer review Not commissioned; externally peer reviewed.

Data sharing statement No additional data are available.

Open Access This is an Open Access article distributed in accordance with the Creative Commons Attribution Non Commercial (CC BY-NC 3.0) license, which permits others to distribute, remix, adapt, build upon this work noncommercially, and license their derivative works on different terms, provided the original work is properly cited and the use is non-commercial. See: http:// creativecommons.org/licenses/by-nc/3.0/

\section{REFERENCES}

1. Manthorpe R, Asmussen K, Oxholm P. Primary Sjögren's syndrome: diagnostic criteria, clinical features, and disease activity. VIth International Symposium on Sjögren's syndrome: Avon Connecticut, USA. J Rheumatol 1997;24(Suppl 50):8-11.

2. Binard A, Devauchelle-Pensec V, Fautrel B, et al. Epidemiology of Sjögren's syndrome: where are we? Clin Exp Rheumatol 2007;25:1-4.

3. Pillemer SR, Matteson EL, Jacobsson LTH, et al. Incidence of physician-diagnosed primary Sjögren's syndrome in residents of Olmsted County, Minnesota. Mayo Clin Proc 2001;76:593-9.

4. Drosos AA, Andonopoulos AP, Costopoulos JS, et al. Prevalence of primary Sjögren's syndrome in an elderly population. Br J Rheumatol 1988;27:123-7. 
5. Hochberg MC, Schein OD, Munoz B, et al. The prevalence of dry eye, dry mouth, autoimmunity and primary Sjögren's syndrome in the general population. Arthritis Rheum 1996;39:S66.

6. Dafni UG, Tzioufas AG, Staikos P, et al. Prevalence of Sjögren's syndrome in a closed rural community. Ann Rheum Dis 1997;56:521-5.

7. Parambil JG, Myers JL, Lindell RM, et al. Interstitial lung disease in primary Sjögren syndrome. Chest 2006;130:1489-95.

8. Parke AL. Pulmonary manifestations of primary Sjögren's syndrome. Rheum Dis Clin North Am 2008;34:907-20.

9. Lin DF, Yan SM, Zhao Y, et al. Clinical and prognostic characteristics of 573 cases of primary Sjögren's syndrome. Chin Med J (Engl) 2010;123:3252-7.

10. Gardiner P, Ward C, Allison A, et al. Pleuropulmonary abnormalities in primary Sjögren's syndrome. J Rheumatol 1993;20:831-7.

11. Deheinzelin D, Capelozzi VL, Kairalla RA. et al. Interstitial lung disease in primary Sjögren's syndrome. Clinical-pathological evaluation and response to treatment. Am J Respir Crit Care Med 1996;154(3 Pt 1):794-9.

12. Ju-Hong S, Hong-Rui L, Weng-Bin X, et al. Pulmonary manifestations in Sjögren's syndrome. Respiration 2009;78:377-86.

13. St Sauver JL, Grossardt BR, Yawn BP, et al. Use of a medical records linkage system to enumerate a dynamic population over time: the Rochester epidemiology project. $A m$ J Epidemiol 2011;173:1059-68.

14. Melton LJ III. History of the Rochester epidemiology project. Mayo Clin Proc 1996;71:266-74.

15. Vitali C, Bombardieri S, Jonsson R. et al. Classification criteria for Sjögren's syndrome: a revised version of the European criteria proposed by the American-European Consensus Group. Ann Rheum Dis 2002;61:554-8.

16. Bongartz T, Nannini C, Medina-Velasquez YF, et al. Incidence and mortality of interstitial lung disease in rheumatoid arthritis: a population-based study. Arthritis Rheum 2010; 62:1583-91.

17. Bergstralh EJ, Offord KP, Chu CP, et al. Technical Report Series No. 49. Calculating incidence, prevalence and mortality rates for Olmsted County, Minnesota: an update. Rochester, (MN): Section of Biostatistics, Mayo Clinic, 1992.

18. McCullagh $\mathrm{P}$, Nelder JA. Generalized linear models. New York: Chapman \& Hall, 1983
19. Gooley TA, Leisenring W, Crowley J, et al. Estimation of failure probabilities in the presence of competing risks: new representations of old estimators. Stat Med 1999;18:695-706.

20. Therneau TM, Offord J. Expected survival based on hazard rates (updated). Technical Report Series No. 63. Rochester, (MN): Mayo Clinic Department of Health Sciences Research, 1999.

21. Alamanos $\mathrm{Y}$, Tsifetaki N, Vulgari PV, et al. Epidemiology of primary Sjögren's syndrome in north-west Greece 1982-2003. Rheumatology 2006;45:187-91.

22. Plesivcnik NM, Rozman B, Hocevar A, et al. Incidence of primary Sjögren's syndrome in Slovenia. Ann Rheum Dis 2004;63:874-6.

23. Skopouli FN, Dafni U, loannidis JP, et al. Clinical evaluation morbidity and mortality of primary Sjögren's syndrome. Semin Arthritis Rheum 2000;29:296-304.

24. Theander E, Manthorpe R, Jacobsson LT. Mortality and cause of death in primary Sjögren's syndrome: a prospective cohort study. Arthritis Rheum 2004:50:1262-9.

25. Ionnidis JP, Vassiliou VA, Moutsopoulos HM. Long term risk of mortality and lymphoproliferative disease and predictive classification of primary Sjögren's syndrome. Arthritis Rheum 2002;46:741-7.

26. Ramos Casals M, Brito-Zeron P, Yague J, et al. Hypocomplementaemia as an immunological marker of morbidity and mortality in patients with primary Sjögren's syndrome. Rheumatology 2005;44:89-94.

27. Brito-Zeron $\mathrm{P}$, Ramos-Casals $\mathrm{M}$, Bova $\mathrm{A}$, et al. Predicting adverse outcomes in primary Sjögren's syndrome: identification of prognostic factors. Rheumatology 2007;46:1359-62.

28. Martens PB, Pillmer SR, Jacobsson LTH, et al. Survivorship in a population based cohort of patients with Sjögren's syndrome 1976-1992. J Rheumatol 1999;26:1296-300.

29. Kruize AA, Hene RJ, van der Heide A, et al. Long term follow up of patients with Sjögren's syndrome. Arthritis Rheum 1996;39:297-303.

30. Shiboski SC, Shiboski CH, Criswell LA, et al. American College of Rheumatology classification criteria for Sjögren syndrome: a data driven, expert consensus approach in the Sjögren International Collaborative Clinical Alliance cohort. Arthritis Care Res 2012;64:475-87.

31. American Thoracic Society, European Respiratory Society. American Thoracic Society/European Respiratory Society International Multidisciplinary Consensus Classification of the Idiopathic Interstitial Pneumonias. Am J Respir Crit Care Med 2002;165:277-304. 